\title{
Recurrence Frequency and Variability Analysis of Fog Events for Planning and Management of Potato in Eastern U.P. India
}

\author{
Nitish Kumar ${ }^{1 *}$, A.K. Singh ${ }^{1}$, S.R. Mishra ${ }^{1}$, Praveen Kumar Singh ${ }^{2}$, \\ Chandan Kumar Singh ${ }^{3}$ and Vikash kumar Singh ${ }^{4}$
}

\author{
${ }^{1}$ Department of Agricultural Meteorology, N.D. University of Agriculture and Technology, \\ Kumarganj, Faizabad -224229(U.P.), India \\ ${ }^{2}$ Department of Vegetable Science, ${ }^{3}$ Department of Plant Pathology, NDUAT Kumarganj, \\ Faizabad-224229 (U.P.), India \\ ${ }^{4}$ Department of Plant Pathology, SHUATS, NAINI Allahabad (U. P.), India \\ *Corresponding author
}

\section{A B S T R A C T}

\begin{tabular}{|l|}
\hline Key w or d s \\
Annual variation of \\
fog, Monthly \\
variation of fog, \\
Fortnightly \\
variation of fog.
\end{tabular}

The recurrence frequency of fog events on annual, decadal, seasonal and fortnightly basis of eastern Uttar Pradesh, Faizabad district were made from long period average data of 1986-2015. From 2012 onwards in December and January months the fog frequency increased exponentially. In terms of percentage of fog frequency during second fortnight (1986-2014), $37 \%$ frequency of occurrence of fog above the normal was recorded in November, $48 \%$ in December and $44 \%$ in January and in month of February it was $68 \%$.Total $33 \%$ fog occurrence was recorded in first decade (1986-1995) $38 \%$ in $2^{\text {nd }}$ decade (1996-2005) i.e. 5\% increase as compared to first decade then after decreased to $29 \%$ in $3^{\text {rd }}$ decade (2006-2015) hence indicated that fog occurrence was oscillating between $29 \%$ to $38 \%$. December and January months were recorded higher days of fog occurrence in each decade. In the decade 1986-95, out of total, $32 \%$ fog days occurred in December, and 30\% in January. While in $2^{\text {nd }}$ decade (1996-2005) it was 29.5 and $42 \%$ in December andJanuary respectively and in $3^{\text {rd }}$ decade it was further increased in December to $36 \%$ but decreased from $42 \%$ to $38 \%$ in January. In Monthly variation December and January months were recorded higher days of fog occurrence in each decade.

\section{Introduction}

Possible impact of climate change on frequency and severity of weather extremes can have a significant impact on agriculture production, but their effect is often unclear, this may be due to interaction with other factors that affect yield and due to lack of precise definitions of relevant weather extremes (Vanoort, 2012). The Climate variability and weather extremes are principal sources of fluctuations of annual productivity of many crops in arid and semi-arid environments. Of the total annual crop losses in world agriculture, many are due to direct weather and climatic effects such as drought, flash floods, untimely rains, frost, hail, and storm. Temperature and precipitation are the major weather variables that determine the variability of crop yields (Bannayan and Sanjani, 2011). Under the impact of future scenario of climate change and global 
warming, the abberent weather and extreme weather events viz., frost, fog, extreme cold and hot weather, hail storm/sleet etc. affect the growth of sensitive rabi crops like potato in India and might be arrested or even reversed, unless effective adaptation measures are evolved for timely intervention. Studies on weather parameters carried out at Central Potato Research Institute Campus, Modipuram in early, main and spring crops for mean leaf hopper population in potato during three different crop seasons, confirmed that early crops planted during September favoured highest development of leaf hoppers followed by main (Oct-Feb) and spring crops (Dec-April) under variable weather conditions. Also a distinct varietal difference was observed in appearance and build-up of leaf hoppers (Sharma and Singh, 2012). Hence disease development was greatly influenced by the weather conditions and intensification occurs at extreme weather condition (Zolfagari et al., 2011). High preparedness, prior knowledge of the timing and magnitude of weather events and climatic anomalies and effective recovery plans will do much to reduce their impact on production levels (Mavi and Tupper, 2004).

\section{Materials and Methods}

Faizabad district of eastern U.P. enjoys sub humid climate and received average annual rainfall about $1036 \mathrm{~mm}$. On an average about 85 per cent of the total rainfall is received during monsoon period i.e. from June to September, However, occasionally 5 to 7 per cent showers occur during winter season. In the district, normally onset of monsoon begins during third week of June and cessation of monsoon occurs by the end of September or $1^{\text {st }}$ week of October (Tripathi et al., 1998). The aberrant weather and extreme weather events viz., fog, frost, extreme cold and hot weather, hail storm /sleet etc affect the growth of sensitive rabi crops like potato in India to the great extent. Hence in order to study the fog recurrence frequency, the data of eastern U.P./faizabad district from 1986-2015 on daily bases has been collected. The recurrence frequency and events of occurrence of fog were analyzed on annual, decadal, seasonal and fortnightly basis for period 1986-2015 from Agromet observatory data located at N.D. University of Agriculture and Technology, Kumarganj, Faizabad, U.P.

\section{Results and Discussion}

The annual and monthly variation of number of days of fog occurrence recorded during1986 -2015 in different years (Table 1) and its variation during crop season (Fig. 1). From table 1, it was revealed that maximum 55 days fog occurred during 1998 followed by 54 days in 1999 and 53 days in 2014. The average number of days of fog events during the recorded period $1986-2015$ was 33.6 or 37 days per year during winter season (Nov to Feb). Fog recurrence during month of January was highest (355 out of 975) followed by December 315, February179 and November 126. The maximum frequency of fog per year 12.5 was recorded in month of January followed by December 10.8 and February 6.17.respectively.

Annual variability of fog days was observed that the annual variation of fog incidence during winter/rabi crop season possess the polynomial cycle of order 3 with increasing amplitude. The average number of fog days in a year i.e. normal days of fog occurrence was 32.86 or 37 days per year in the area. From 2012 onwards fog frequency rapidly increased exponentially. This was the alarming situation for the crops sensitive to the fog, and high relative humidity. More number of occurrences of fog in a season reduced the duration of bright sunshine hours and increased the relative humidity. This ultimately not only affects the crop growth and development but also creates the 
congenial environment to invite for incidence of insect- pest and diseases.

Variation of fog during peak period of its occurrence in January and December (Figs. 2 and 3) both possess the polynomial cycle of order 3 with increasing amplitude. On the basis of long term data for the period 19862015 , the average number of fog days in the month of January i.e. normal days of fog occurrence was 12.24 days and in month of December it was 10.86 or 11 days in the area. From 2012 onwards in both months (December and January) the fog frequency rapidly increased exponentially.

This is the peak period for occurrence of late blight in potato, powdery mildew in pea crop etc. More number of fog days during January increases the relative humidity and shortened the bright sunshine hour and adversely affect the flower initiation and number of flower formation in pigeon pea. Hence intensification of crop protection measures is required.

Fortnightly variation (Table 2) of fog during November to February (1986-2014) revealed that the frequency of occurrence of fog events in first fort night during month of November was 10 days above the normal (2.13) while during the month of December it was 13 days but in January it was same as that of December i.e.13 days, and in month of February fog events was 14 days above the normal. In second fort night during month of November (1986-2014) 11 days fog event was observed above the normal (2.20) while during the month of December it was 14 days above the normal, month of January 13 days, and month of February it was quite high 20 days average fog events above the normal were recorded. In terms of percentage of fog during first fort night (1986-2014), $34 \%$ frequency of occurrence of fog above the normal was recorded in November, $44 \%$ in December and same in January $44 \%$ and month of February it was quite high as compare to November (48\%). Similarly in terms of percentage of fog during second fort night (1986-2014), $37 \%$ frequency of occurrence of fog above the normal was recorded in November, $48 \%$ in December and $44 \%$ in January and month of February it was $68 \%$.

The characteristic feature of the variability of fog days during peak period of its occurrence in the Month of December and January (Figs. 4 and 5) indicate annual variation of fog incidence during January and December both possess the polynomial cycle of order 3 with increasing amplitude.

On the basis of long term data for the period 1986-2015, the average number of fog days in the month of January in first fortnight i.e. normal days of fog occurrence was 6.5 days and in second fortnight it was 5.6 days in the area. From 2012 onwards in both fortnights, the fog frequency rapidly increased exponentially.

The decadal variation of fog occurrence on monthly basis has been depicted in table 3 and 5 for period 1986-1995, 1996-2005 and 2006-2015 respectively. From the table, it was observed that total number of fog days during this decade was 324 or 32 days once in a year.

Again December month was reported to possess maximum number days of fog days (103) followed by January 97 days, February 81days and November 37 days only. Maximum number (49 days) fog occurred during 1987 followed by 1994 (41 days) and 1990 (33 days) in each year. As far as frequency of fog occurrence is concerned, December month possess highest frequency of 10.3 days / year followed by 9.7 day in January, 8.1 day in February. This showed that December and January are at par for fog occurrence the area during this decade. 
Table.1 Annual and monthly variation of number of days of fog occurrence

\begin{tabular}{|l|l|l|l|l|l|}
\hline \multicolumn{7}{|c|}{ Months } \\
\hline years & NOV & DEC & JAN & FEB & TOTAL \\
\hline $\mathbf{1 9 8 6}$ & 2 & 12 & 6 & 11 & $\mathbf{3 1}$ \\
\hline $\mathbf{1 9 8 7}$ & 4 & 7 & 27 & 11 & $\mathbf{4 9}$ \\
\hline $\mathbf{1 9 8 8}$ & 0 & 16 & 0 & 4 & $\mathbf{2 0}$ \\
\hline $\mathbf{1 9 8 9}$ & 7 & 6 & 8 & 9 & $\mathbf{3 0}$ \\
\hline $\mathbf{1 9 9 0}$ & 7 & 10 & 0 & 16 & $\mathbf{3 3}$ \\
\hline $\mathbf{1 9 9 1}$ & 4 & 10 & 6 & 6 & $\mathbf{2 6}$ \\
\hline $\mathbf{1 9 9 2}$ & 4 & 10 & 10 & 9 & $\mathbf{3 3}$ \\
\hline $\mathbf{1 9 9 3}$ & 4 & 11 & 11 & 3 & $\mathbf{2 9}$ \\
\hline $\mathbf{1 9 9 4}$ & 4 & 12 & 16 & 9 & $\mathbf{4 1}$ \\
\hline $\mathbf{1 9 9 5}$ & 7 & 9 & 13 & 3 & $\mathbf{3 2}$ \\
\hline $\mathbf{1 9 9 6}$ & 1 & 3 & 9 & 6 & $\mathbf{1 9}$ \\
\hline $\mathbf{1 9 9 7}$ & 11 & 9 & 15 & 2 & $\mathbf{3 7}$ \\
\hline $\mathbf{1 9 9 8}$ & 9 & 22 & 18 & 6 & $\mathbf{5 5}$ \\
\hline $\mathbf{1 9 9 9}$ & 3 & 16 & 22 & 13 & $\mathbf{5 4}$ \\
\hline $\mathbf{2 0 0 0}$ & 2 & 4 & 18 & 14 & $\mathbf{3 8}$ \\
\hline $\mathbf{2 0 0 1}$ & 2 & 17 & 10 & 2 & $\mathbf{3 1}$ \\
\hline $\mathbf{2 0 0 2}$ & 12 & 9 & 15 & 6 & $\mathbf{4 2}$ \\
\hline $\mathbf{2 0 0 3}$ & 0 & 13 & 30 & 8 & $\mathbf{5 1}$ \\
\hline $\mathbf{2 0 0 4}$ & 3 & 12 & 8 & 1 & $\mathbf{2 4}$ \\
\hline $\mathbf{2 0 0 5}$ & 0 & 5 & 12 & 5 & $\mathbf{2 2}$ \\
\hline $\mathbf{2 0 0 6}$ & 9 & 7 & 3 & 3 & $\mathbf{2 2}$ \\
\hline $\mathbf{2 0 0 7}$ & 0 & 3 & 3 & 11 & $\mathbf{1 7}$ \\
\hline $\mathbf{2 0 0 8}$ & 0 & 7 & 8 & 4 & $\mathbf{1 9}$ \\
\hline $\mathbf{2 0 0 9}$ & 6 & 7 & 12 & 0 & $\mathbf{2 5}$ \\
\hline $\mathbf{2 0 1 0}$ & 9 & 12 & 6 & 4 & $\mathbf{3 1}$ \\
\hline $\mathbf{2 0 1 1}$ & 8 & 19 & 17 & 3 & $\mathbf{4 7}$ \\
\hline $\mathbf{2 0 1 2}$ & 2 & 9 & 10 & 5 & $\mathbf{2 6}$ \\
\hline $\mathbf{2 0 1 3}$ & 3 & 14 & 18 & 3 & $\mathbf{3 8}$ \\
\hline $\mathbf{2 0 1 4}$ & 3 & 24 & 24 & 2 & $\mathbf{5 3}$ \\
\hline Total & $\mathbf{1 2 6}$ & $\mathbf{3 1 5}$ & $\mathbf{3 5 5}$ & $\mathbf{1 7 9}$ & $\mathbf{9 7 5}$ \\
\hline & & & & & \\
\hline & & & & & \\
\hline
\end{tabular}


Table.2 Fortnightly variation of fog during November to February (1986-2014)

\begin{tabular}{|c|c|c|c|c|c|c|c|}
\hline YEAR & Fortnight & NOV & DEC & JAN & FEB & $\begin{array}{l}\text { Total } \\
\text { Fortnight } \\
\end{array}$ & $\begin{array}{l}\text { Monthly } \\
\text { Fortnight }\end{array}$ \\
\hline \multirow{2}{*}{1986} & FF- & 1 & 2 & 3 & 11 & 17 & \multirow[t]{2}{*}{31} \\
\hline & SF- & 1 & 10 & 3 & 0 & 14 & \\
\hline \multirow[t]{2}{*}{1987} & FF- & 3 & 4 & 13 & 4 & 24 & \multirow[t]{2}{*}{49} \\
\hline & SF- & 1 & 3 & 14 & 7 & 25 & \\
\hline \multirow[t]{2}{*}{1988} & FF- & 0 & 8 & 0 & 2 & 10 & \multirow[t]{2}{*}{20} \\
\hline & SF- & 0 & 8 & 0 & 2 & 10 & \\
\hline \multirow[t]{2}{*}{1989} & FF- & 5 & 0 & 8 & 8 & 21 & \multirow[t]{2}{*}{30} \\
\hline & SF- & 2 & 6 & 0 & 1 & 09 & \\
\hline \multirow[t]{2}{*}{1990} & FF- & 1 & 10 & 0 & 6 & 17 & \multirow[t]{2}{*}{33} \\
\hline & SF- & 6 & 0 & 0 & 10 & 16 & \\
\hline \multirow[t]{2}{*}{1991} & FF- & 1 & 0 & 1 & 1 & 03 & \multirow{2}{*}{26} \\
\hline & SF- & 3 & 10 & 5 & 5 & 23 & \\
\hline \multirow{2}{*}{1992} & FF- & 2 & 6 & 3 & 5 & 16 & \multirow[t]{2}{*}{33} \\
\hline & SF- & 2 & 4 & 7 & 4 & 17 & \\
\hline 1993 & FF- & 3 & 6 & 2 & 0 & 11 & 29 \\
\hline & SF- & 1 & 5 & 9 & 3 & 18 & \\
\hline 1994 & FF- & 4 & 7 & 9 & 6 & 26 & 41 \\
\hline & SF- & 0 & 5 & 7 & 3 & 15 & \\
\hline 1995 & FF- & 4 & 0 & 12 & 2 & 18 & 32 \\
\hline & SF- & 3 & 9 & 1 & 1 & 14 & \\
\hline 1996 & FF- & 1 & 0 & 7 & 5 & 13 & 19 \\
\hline & SF- & 0 & 3 & 2 & 1 & 06 & \\
\hline 1997 & FF- & 4 & 0 & 9 & 1 & 14 & 37 \\
\hline & SF- & 7 & 9 & 6 & 1 & 23 & \\
\hline 1998 & FF- & 4 & 7 & 15 & 2 & 28 & 55 \\
\hline & SF- & 5 & 15 & 3 & 4 & 27 & \\
\hline 1999 & FF- & 0 & 3 & 15 & 10 & 28 & 54 \\
\hline & SF- & 3 & 13 & 7 & 3 & 26 & \\
\hline 2000 & FF- & 1 & 1 & 4 & 12 & 18 & 38 \\
\hline & SF- & 1 & 3 & 14 & 2 & 20 & \\
\hline 2001 & FF- & 2 & 7 & 7 & 1 & 17 & 31 \\
\hline & SF- & 0 & 10 & 3 & 1 & 14 & \\
\hline 2002 & FF- & 2 & 0 & 6 & 6 & 14 & 42 \\
\hline & SF- & 10 & 9 & 9 & 0 & 28 & \\
\hline 2003 & FF- & 0 & 3 & 14 & 4 & 21 & 51 \\
\hline & SF- & 0 & 10 & 16 & 4 & 30 & \\
\hline 2004 & FF- & 0 & 0 & 6 & 1 & 07 & 24 \\
\hline & SF- & 3 & 12 & 2 & 0 & 17 & \\
\hline 2005 & FF- & 0 & 1 & 3 & 2 & 06 & 22 \\
\hline & SF- & 0 & 4 & 9 & 3 & 16 & \\
\hline 2006 & FF- & 9 & 3 & 0 & 3 & 15 & 22 \\
\hline & SF- & 0 & 4 & 3 & 0 & 07 & \\
\hline 2007 & FF- & 0 & 1 & 1 & 8 & 10 & 17 \\
\hline & SF- & 0 & 2 & 2 & 3 & 07 & \\
\hline 2008 & FF- & 0 & 5 & 1 & 2 & 08 & 19 \\
\hline & SF- & 0 & 2 & 7 & 2 & 11 & \\
\hline 2009 & FF- & 2 & 1 & 8 & 0 & 11 & 25 \\
\hline & SF- & 4 & 6 & 4 & 0 & 14 & \\
\hline 2010 & FF- & 4 & 5 & 4 & 4 & 17 & 31 \\
\hline & SF- & 5 & 7 & 2 & 0 & 14 & \\
\hline 2011 & FF- & 5 & 11 & 14 & 2 & 32 & 47 \\
\hline & SF- & 3 & 8 & 3 & 1 & 15 & \\
\hline 2012 & FF- & 1 & 2 & 8 & 5 & 16 & 26 \\
\hline & SF- & 1 & 7 & 2 & 0 & 10 & \\
\hline 2013 & FF- & 1 & 6 & 6 & 1 & 14 & 38 \\
\hline & SF- & 2 & 8 & 12 & 2 & 24 & \\
\hline 2014 & FF- & 2 & 10 & 12 & 1 & 25 & 53 \\
\hline & SF- & 1 & 14 & 12 & 1 & 28 & \\
\hline Total & FF & 62 & 109 & 191 & 115 & 477 & 975 \\
\hline & SF & 64 & 206 & 164 & 64 & 498 & \\
\hline & FF & 2.13 & 3.75 & 6.5 & 3.9 & 16.44 & 33.62 \\
\hline Normal & SF & 2.20 & 7.10 & 5.6 & 2.20 & 17.17 & \\
\hline
\end{tabular}


Table.3 Monthly variation of frequency percentage of fog in first and second Fortnight, during (1986-2014)

\begin{tabular}{|c|c|c|c|l|}
\hline \multicolumn{5}{|c|}{ Months } \\
\hline Fortnight & November & December & January & February \\
\hline First & $10(34)$ & $13(44)$ & $13(44)$ & $14(48)$ \\
\hline Second & $11(37)$ & $14(48)$ & $13(44)$ & $20(68)$ \\
\hline
\end{tabular}

Fig.1 Annual variation of fog during crop season

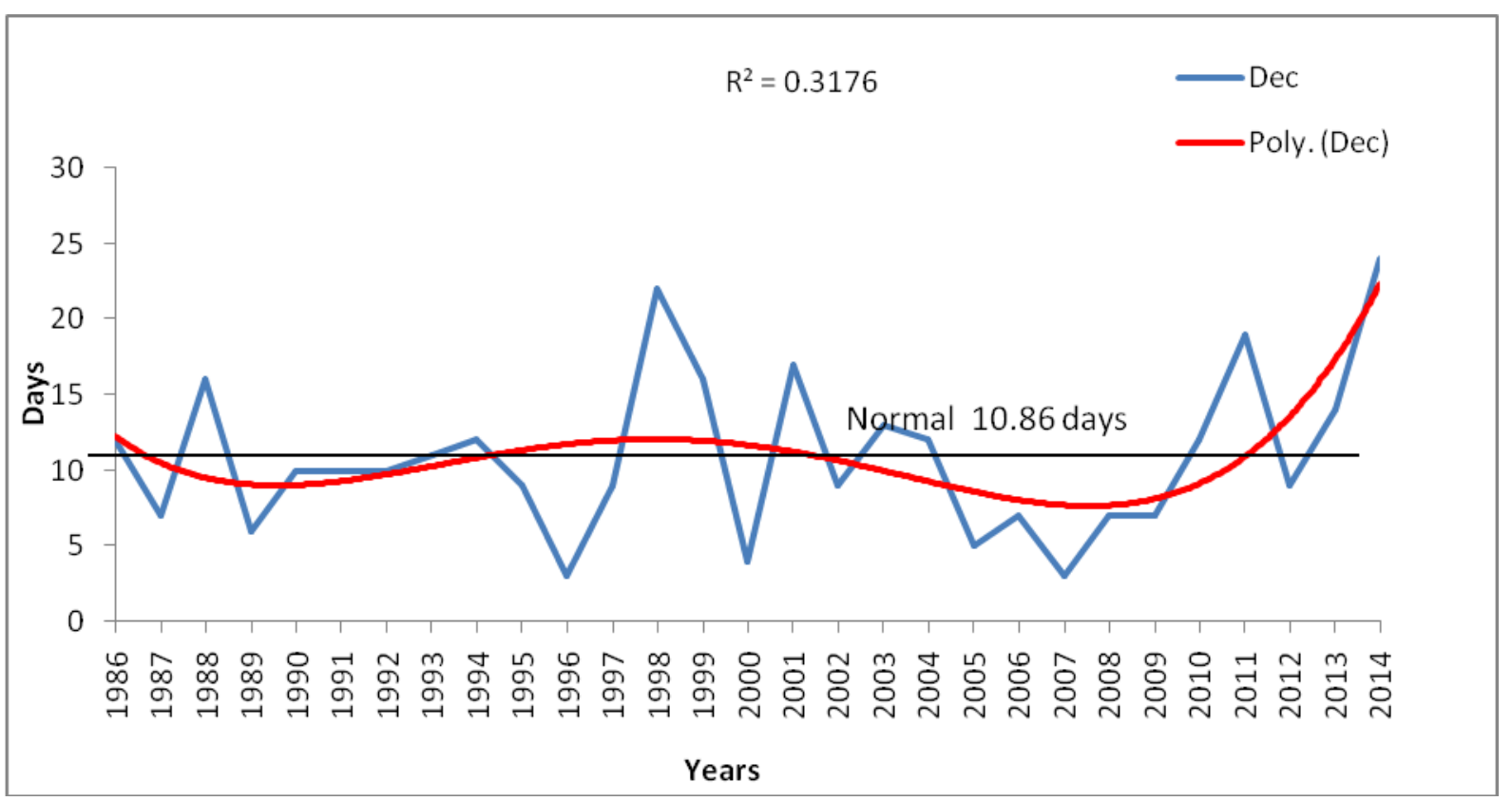

Fig.2 Variation of fog during peak period of December

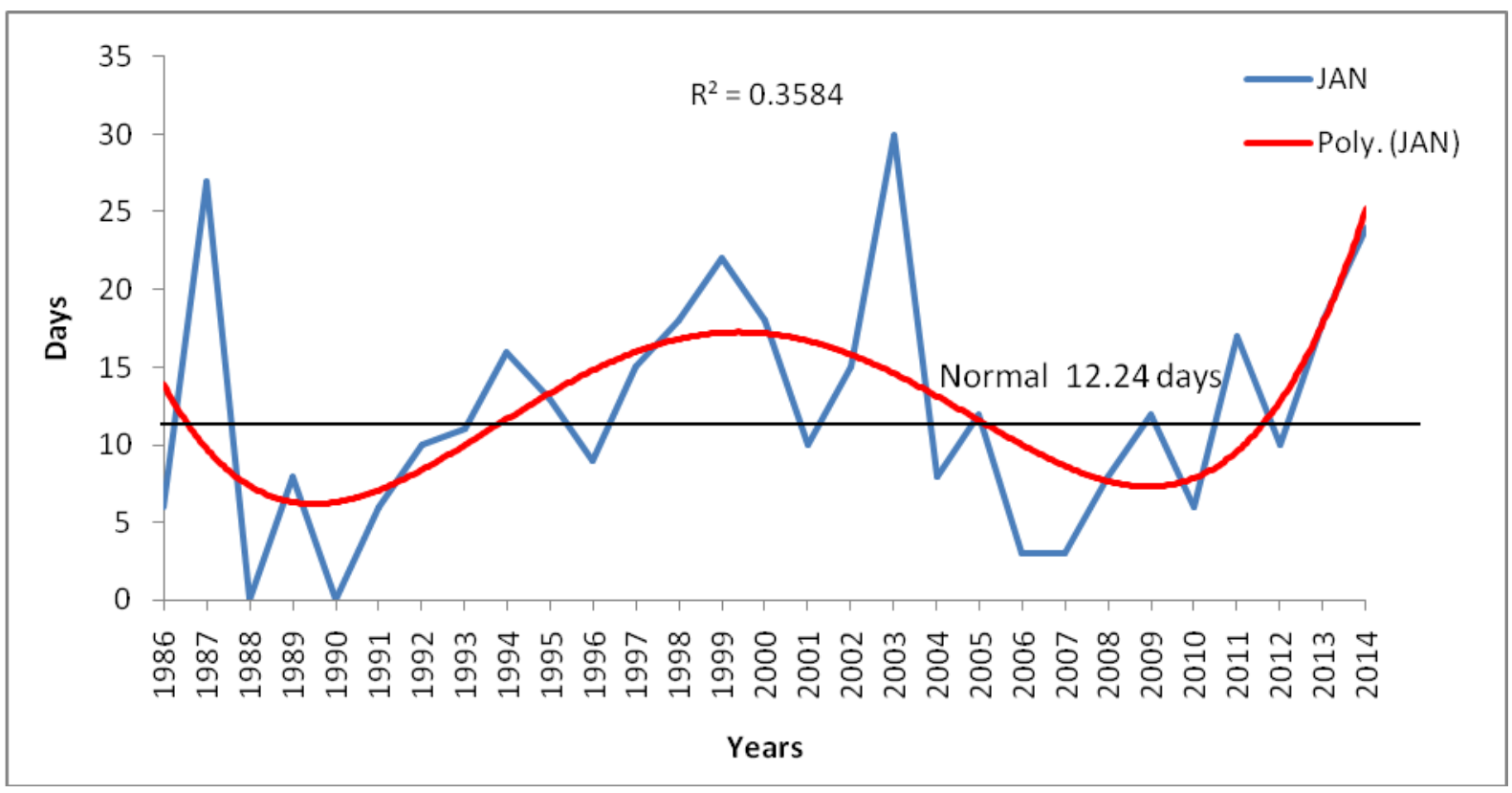


Fig.3 Fog during month of January (Second fortnight) 1986-2014

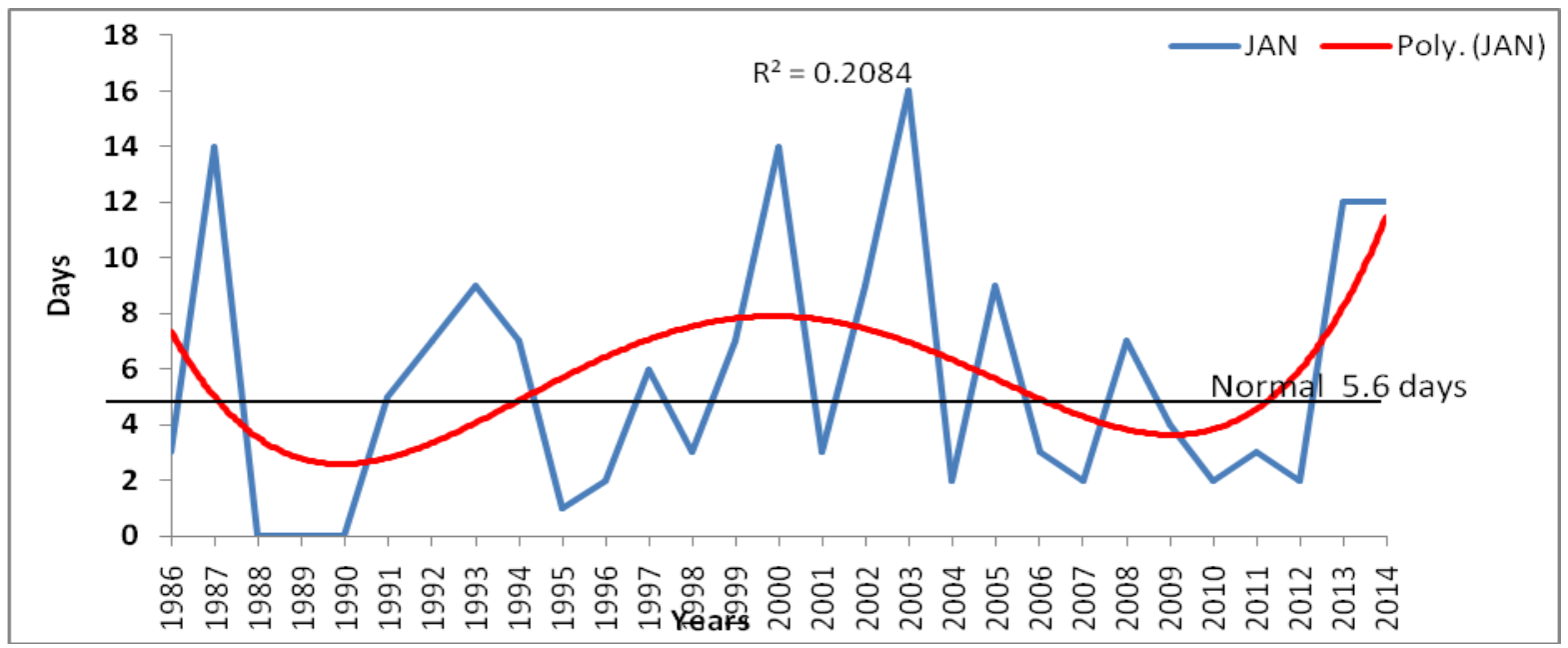

Fig.4 Fog during month of January (First fortnight) 1986-2014

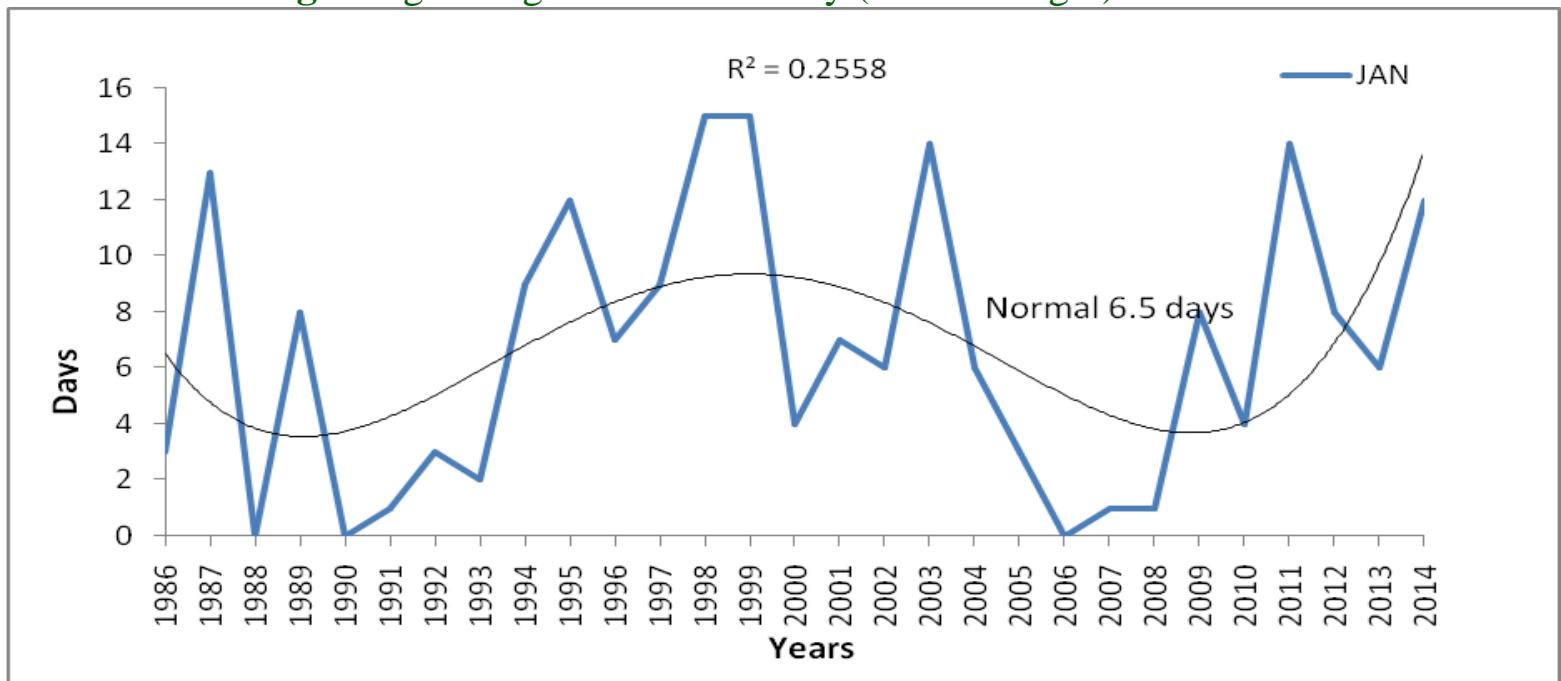

Fig.5 Decadal variation of fog occurance

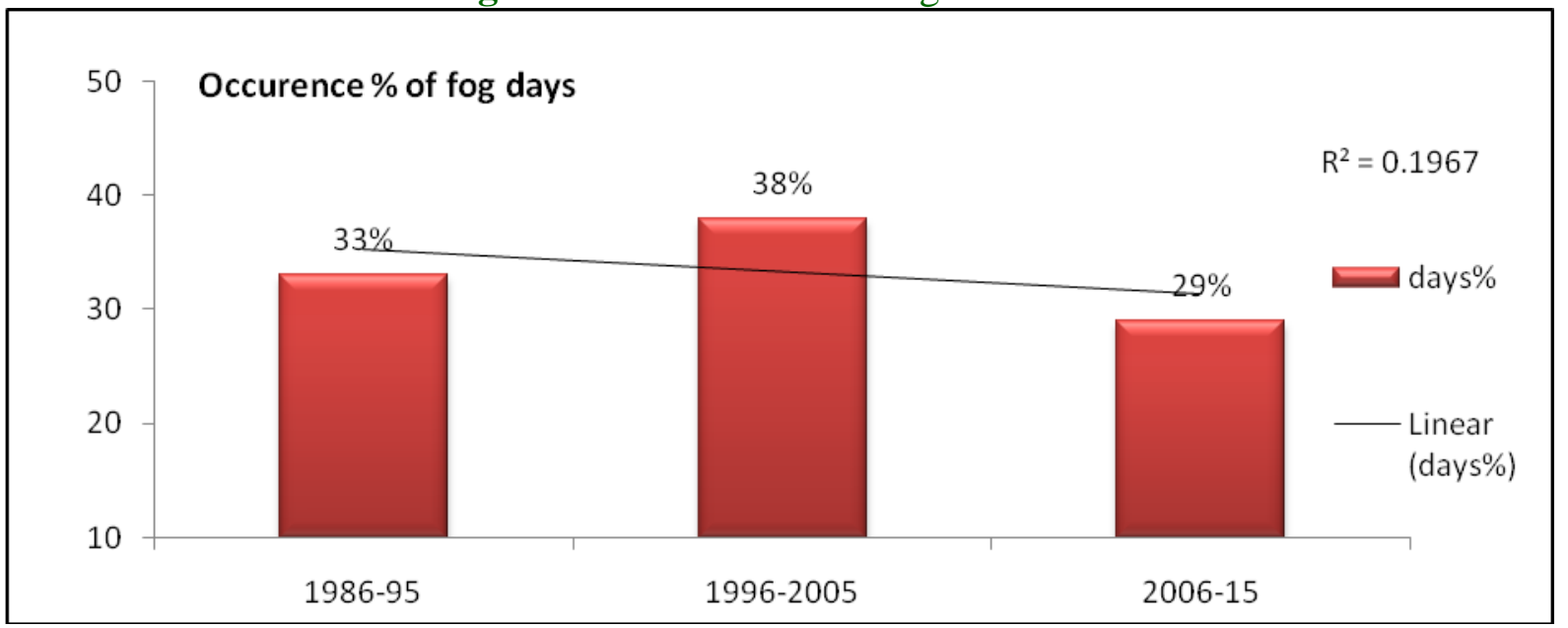


Fig.6 Monthly occurrenceof fog days (\%) during December and January in decade

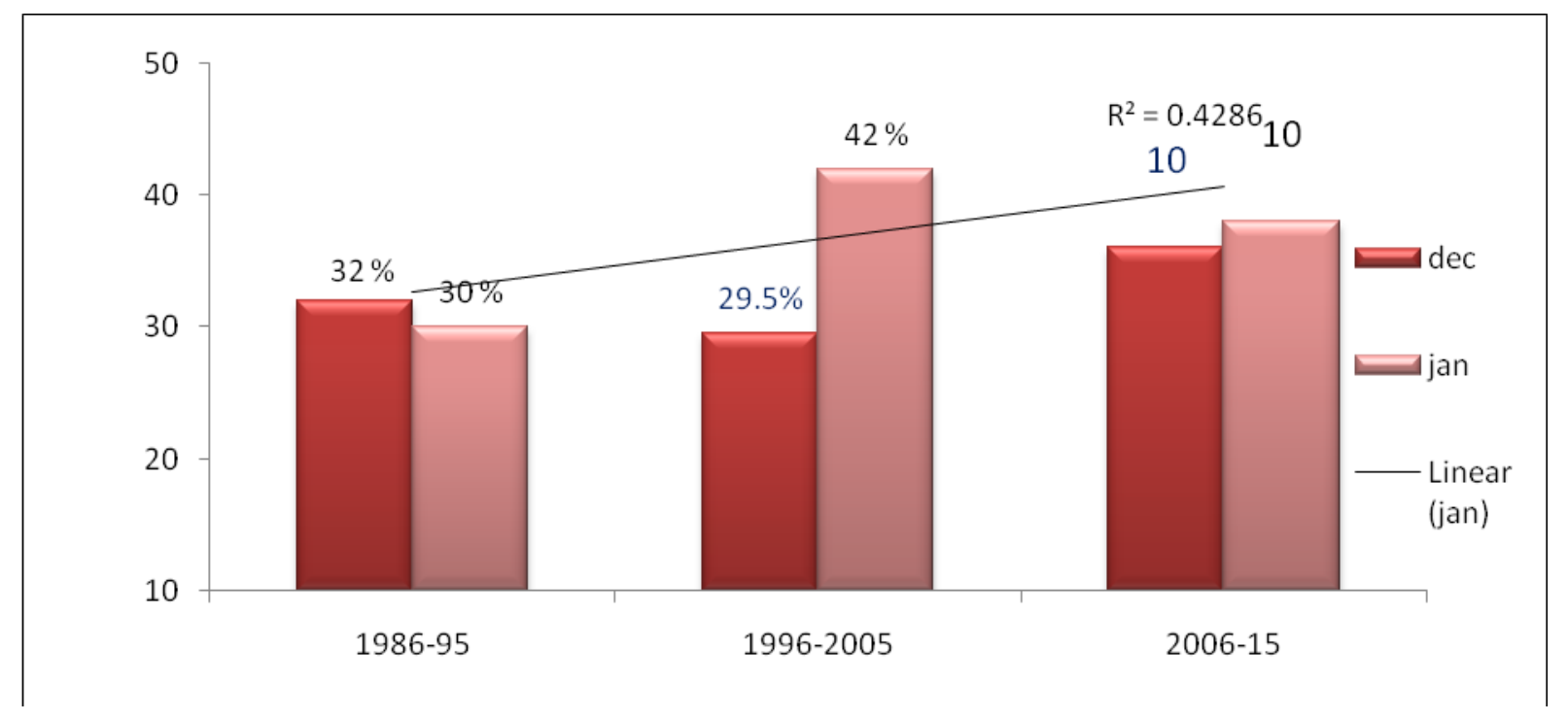

The decadal variation of the fog occurrence has been shown in Table. 3 for period 19862014. From table it was observed that total number of fog during this decade was 373 i.e. 37.7 or 38 day once in a year, contained more number as compare to previous decade (198695)i.e.324 days. Again January month was reported to possess maximum number of fog days 157 followed by December 110 days, February 63 and November 43 days respectively, Maximum number (55) of fog days occurred during 1998, followed by 1999 (54) days and 2003 (51) days. From the observation of fog occurrence data of both decade it was recorded that the fog frequency during this decade increased to 373 from 324 as compared to previous decade (1986-95) i.e. $15 \%$ increase. Similarly fog increment of $6 \%$ was reported in January month followed by December $7 \%$ and November 2\%. But 22\% fog frequency reduced during February in this decade as compared to previous decade. This showed that fog occurrence shifted from February to January and December, affecting the crops at vegetative stage of rabi crops.

The decadal variation of the fog occurrence has been shown in Table 2 for period 20062015. From table it was observed that total number of fog days during this decade was 284 i.e. 28.4 or 29 days once in a year. Again January month was reported to possess maximum number of fog days (107) followed by December 102 days, November 40 days, and February 35 days. Maximum number of fog days was 53 days during 2014 followed by 2011(47) days and 2013(38) days during this decade. During November, December, January and February, all months, the number of fog days was considerably reduced in this decade as compared to previous decade (1996-2005).

In addition, the decadal and monthly variability analysis of fog occurrence as shown in figure 6 which revealed that out of total days of fog occurrence $33 \%$ fog days occurred in first decade (1986-1995), $38 \%$ in $2^{\text {nd }}$ decade (1996-2005) i.e. 5\% increase in this decade as compared to first decade then after decreased to $29 \%$ in $3^{\text {rd }}$ decade (20062015). This clearly indicated that fog occurrence was oscillating between $29 \%$ and 38\% i.e. within the range of $9 \%$ between 1996 and 2015 in the area.

Monthly variation as shown in figure 7 revealed that December and January months 
were recorded higher days of fog occurrence in each decade including reporting period of 1986-2015. In the decade 1986-95, out of total $32 \%$ fog days occurred in December, $30 \%$ in January fog days were recorded. While in $2^{\text {nd }}$ decade (1996-2005) it was 29.5 and $42 \%$ in December and January respectively and in $3^{\text {rd }}$ decade it was further increased in December to $36 \%$ but decreased from $42 \%$ to $38 \%$ in January.

From the above study, it may be finally concluded that fog frequency both in terms of number of events of fog days and fog frequency was increased. December and January were peak months for maximum fog occurrence in past two decade but in recent decade (2006-2015) fog occurrence in February month was appeared in increasing trend. This ultimately affected the fog sensitive rabi crops specially pulses, oil seeds and potato etc. Hence, crop planning, management and remedial measures to combat the adverbs effect of fog is necessarily required.

\section{References}

Bannayan, M. and Sanjani, S. 2011. Weather conditions associated with irrigated crops in an arid and semi-arid environment. Agri. Forest Meteorol., 151(12): 1589- 1598.

Mavi, H.S. and Tupper, G.J. 2004. Agrometeorology Principles and Applications of Climate. Studies in Agriculture, Food Products Press, New York.

Sharma, Vineet and Singh, B.P. 2012. Effect of varieties, seasons and weather on population buildup of leaf hopper (Amrasca devastans Distant) on potato crop. Potato J., 39(1): 23-30.

Tripathi, P., Rizvi S.M.A. and Tripathi B.R. 1998. Agroclimatic Atlas of eastern (U.P.). Department of Agricultural Meteorology, N.D.U.A.T., Kumarganj Faizabad.

Vanoort, P.A.J. and Timmermans, B.G.H. and Meinke, H. and Van Ittersum, M.K. 2012. Weather extremes affecting potato production in the Netherlands. Eur. J. Agron., 37(1) pp. 11-12.

Zolfagari, A., Antonenko, V.V., Zaitsev, D.V. and Zashchita, Karantin Rastenii. 2011. Late and early blight of potato and tomato under the abnormal weather conditions of Moscow region. Izdatel'stvo Kolos, 12.

\section{How to cite this article:}

Nitish Kumar, A.K. Singh, S.R. Mishra, Praveen Kumar Singh, Chandan Kumar Singh and Vikash kumar Signh. 2017. Recurrence Frequency and Variability Analysis of Fog Events for Planning and Management of Potato in Eastern U.P. India Int.J.Curr.Microbiol.App.Sci. 6(6): 1423-1431. doi: https://doi.org/10.20546/ijcmas.2017.606.167 